ORIGINAL ARTICLE

\title{
Gender differences in habitual activity in children with cystic fibrosis
}

\author{
H C Selvadurai, C J Blimkie, P J Cooper, C M Mellis, P P Van Asperen
}

Arch Dis Child 2004;89:928-933. doi: 10.1136/adc.2003.034249

See end of article for authors' affiliations ....................

Correspondence to: Dr H C Selvadurai, Department of Respiratory Medicine, Hospital for Sick Children, 555 University Avenue, Toronto, Ontario, Canada M5G IX8; Hiran. Selvadurai@sickkids.ca

Accepted 19 January 2004
Aims: (1) To compare habitual activity levels in prepubescent and pubescent boys and girls with different degrees of CF lung disease severity and healthy controls. (2) To assess the relation between habitual activity levels and measures of fitness, lung function, nutrition, pancreatic status, and quality of life. Methods and Results: A total of 148 children (75 girls and 73 boys) with CF and matched controls were studied. Regardless of disease severity, there were no differences in habitual activity between prepubescent boys and girls with CF. Pubescent boys with CF were significantly more active than girls with the same degree of disease severity. There were no significant differences in habitual activity between prepubescent children with CF and controls. Pubescent children with mild CF were significantly more active than controls, but those with moderate to severe disease were less active than controls. The best correlates with habitual activity levels were anaerobic power, aerobic capacity, and quality of life. In children with moderate to severe disease, nutrition status correlated significantly with activity levels. The impact of pancreatic status on activity levels and other measures of fitness was most apparent in pubescent girls. Conclusion: Gender differences in habitual activity were evident only after the onset of puberty. The impact of pancreatic insufficiency on measures of fitness and habitual activity was greatest in pubescent females. The reason for this gender difference may be an interplay of genetic, hormonal, and societal factors and is the focus of a longitudinal study.
$\mathrm{P}$ hysical activity is an integral part of the growth and development of children. ${ }^{1}$ Exercise capacity may be limited in patients with cystic fibrosis (CF) with respiratory $^{2}$ or nutritional compromise. ${ }^{34}$ Inactivity itself results in deconditioning, and a negative feedback loop is formed, making physical activity even more difficult.

Life expectancy among patients with cystic fibrosis (CF) has improved dramatically over the past twenty years. ${ }^{56}$ However, there remains a significant gender difference in survival rates, with females with CF under the age of 20 years being significantly more likely to die than males of the same age. $^{7}$ While nutritional status, pulmonary function, and airway microbiology were independent predictors of survival, none of these parameters account for the gender difference in survival rates. ${ }^{5}$

As aerobic capacity is an important predictor of survival, ${ }^{8}$ the fact that girls with CF have a lower peak aerobic capacity than boys with CF of the same age ${ }^{9}$ may be of relevance. Moreover, compared to reference values obtained in healthy girls, girls with moderate to severe CF related lung disease have a significantly lower peak aerobic capacity. ${ }^{5}$ This finding has been thought to be due to reduced daily physical activity levels and nutritional status in girls with CF. ${ }^{5}$

Maintaining high levels of physical activity is an important objective in the management of CF. Nixon and colleagues ${ }^{10}$ showed in 1992 that aerobic fitness is an independent predictor of survival in CF and that CF patients who had active lifestyles had more slowly progressive disease.

As osteoporosis has been recognised in patients with CF, it is of note that increased physical activity levels have been shown to improve bone mineral density. ${ }^{11}$ Furthermore, aerobic fitness correlates well with quality of life in CF. ${ }^{12}$ Two previous studies have shown that activity levels were similar in children with mild CF and healthy subjects. ${ }^{13} 14$ Unfortunately, these studies had very limited sample sizes and this precluded analysis of gender differences in habitual activity. In addition, activity levels of patients with moderate to severe disease were not studied. As the principal factors that limit exercise capacity of patients with CF, such as respiratory and nutritional compromise, become evident in more severe disease, there is clearly a need to study the activity levels of this group of patients. In addition, previous studies have estimated habitual activity from self report questionnaires. The reliability of such questionnaires in children with chronic conditions such as CF is unknown.

The purpose of this study was twofold. First, we aimed to compare the activity levels of prepubescent and pubescent boys and girls with different grades of CF pulmonary disease severity and healthy controls. Second, we aimed to determine the relation between activity levels in children with CF with quality of life, aerobic capacity, anaerobic power, lung function, and nutritional status. In analysing the effect of nutrition, we sought to evaluate the impact of pancreatic function on habitual activity.

The hypotheses were: (1) that boys with CF are more active than girls with CF; (2) that children with more severe CF disease would be less active than healthy controls; and (3) that pancreatic sufficient children with CF would have higher habitual activity levels.

\section{METHODS \\ Subjects}

Children aged between 9 and 17 years that attended the CF clinic at The Children's Hospital at Westmead, Sydney, Australia, were randomly selected for the study. The randomisation was performed using medical record numbers and uniform random numbers generated by the Numerical Algorithms Group routines GO5CBF and GO5CAF. ${ }^{15}$ The only exclusion criteria were if there had been a history of pulmonary exacerbation in the three months prior to the

Abbreviations: BMP, body mass percentile; $C F$, cystic fibrosis; $\mathrm{FEV}$, forced expiratory volume; $\mathrm{MJ}$, megajoules; PI, pancreatic insufficient; PS, pancreatic sufficient 
study. Pulmonary exacerbation was defined as increased cough and purulent sputum, in a child with malaise. An abnormal chest $x$ ray, weight loss, and generalised malaise were frequently associated with a pulmonary exacerbation. The control group was matched for age ( \pm 6 months), gender, and Tanner pubertal stage, ${ }^{16}$ and consisted of healthy children from surrounding schools. ${ }^{17}$ This study was approved by the Research Ethics Committee of the Royal Alexandra Hospital for Children, and written consent was obtained from all participants and their parents where applicable.

\section{Study design}

Forced expiratory volume in one second $\left(\mathrm{FEV}_{1}\right)$ was used to classify the severity of CF lung disease for each child. Those with an $\mathrm{FEV}_{1}$ of $\geqslant 70 \%$ predicted lung function were classified as having mild lung disease. Those with an $\mathrm{FEV}_{1}$ of $<70 \%$ predicted lung function were classified as having moderate to severe lung disease. All children in the study completed the modified Bouchard activity diary. ${ }^{18}$ The activity diary comprised a record of the dominant activity of each 15 minute period of the day and night. Children completed the diaries for two weeks. To obtain an objective measure of habitual activity, each child also wore a validated accelerometer, ${ }^{19-21}$ WAM 7164 (Computer Science and Applications, Shalimar, Florida) on the same days the activity diary was completed.

Anthropometric details such as weight (in kilograms using an electronic scale, Metler IDI Multimap, Tiel, Netherlands) and height (height in metres using Holtain stadiometer, Crymich, UK) was recorded. In addition, skinfold assessments $^{22}$ were recorded for each child. Children completed a self assessment of their pubertal stage by reviewing standardised Tanner charts. ${ }^{16}$ Using definitions provided by Tanner and colleagues, ${ }^{16}$ children with a Tanner stage of $\leqslant 1$ for pubic hair or breast development, were classified as being prepubescent, and children with a Tanner stage of $\geqslant 2$ for pubic hair or breast development were classified as pubescent. The children with CF and their parents completed a validated quality of wellbeing assessment. ${ }^{23}$ Peak aerobic capacity was assessed using the modified Bruce protocol ${ }^{24}$ on a treadmill (Cardiovit 100, Schiller, Switzerland). Anaerobic power was measured by the Wingate test, ${ }^{25}$ using an electronically braked cycle ergometer (Lode Ergometer, Pro Med, Canada). Measurements of $\mathrm{FEV}_{1}$ and forced vital capacity (FVC) were obtained (Sensormedics 2800 Autobox, Yorba Linda, CA) and expressed as percentage of predicted normal values. ${ }^{26}$

\section{Data analysis}

The body mass index was expressed as a percentage of the theoretical body mass index of a child of the same age and gender growing along the 50th centile for weight and height. This value was termed the body mass percentile (BMP).

The energy costs allotted to the activities in this study were adopted from the reported reference values. ${ }^{27}{ }^{28}$ In order to analyse daily energy expenditure, the children were divided into four groups depending on their gender (male or female) and pubertal stage (prepubescent or pubescent). This was necessary, as normative studies using doubly labelled water in healthy children, showed that daily energy expenditure varied according to sex of the child and whether puberty has been attained. ${ }^{29}$

The differences between boys and girls with CF and who were healthy were assessed by analysis of covariance (ANCOVA). The relations between activity levels and aerobic capacity, anaerobic power, pulmonary function, nutrition, and quality of life were examined using Spearman rank order correlational analysis. Activity levels were divided into quartiles, with $25 \%$ being the lowest activity level and $100 \%$ the highest activity. Multiple linear regression analysis was used to assess the relation between the activity quartiles and the other parameters of assessment. A subgroup analysis was performed to assess the effect of preserved pancreatic function. Each child who was pancreatic sufficient (PS) was matched for gender, age, and disease severity with two children who were pancreatic insufficient (PI). This was done to increase the power of the subanalysis. A matched sample comparison was made of the mean aerobic capacity, quality of life, BMP, and activity levels. Statistical significance was assigned to comparisons where the $\mathrm{p}$ value was less than 0.05 .

\section{RESULTS}

\section{Demographics}

A total of 159 children with CF agreed to participate in the study. However, 11 were excluded on the basis of a recent pulmonary exacerbation; 148 children ( 75 girls and 73 boys) with CF and 148 matched controls completed all aspects of the study. There were no significant differences in demographic details between controls and subjects (table 1). The mean age in the prepubescent group with CF and controls was $10.9(0.9)$ and $11.0(0.8)$ years, respectively. The mean $\mathrm{FEV}_{1}$ in girls and boys in the prepubescent group with mild CF lung disease was $96.2 \%$ (3.4) (range $82.0-110.0 \%$ ) and $97.3 \%$ (4.1) (range $85.0-107.0 \%$ ) respectively. The mean $\mathrm{FEV}_{1}$ in prepubescent girls and boys with moderate to severe CF lung disease was $66.2 \%$ (7.0) and $64.5 \%$ (6.1) respectively. The mean age in the pubescent group with CF and controls was 14.3 (1.4) and 14.2 (1.3) years, respectively. The mean $\mathrm{FEV}_{1}$ in pubescent girls and boys with mild CF lung disease was $92.4 \%$ (4.6) (range $80.0-106.0 \%$ ) and $94.4 \%$ (4.3) (range $81.0-108.0 \%$ ) respectively. The mean $\mathrm{FEV}_{1}$ in pubescent girls and boys with moderate to severe CF lung disease was $56.2 \%$ (8.2) and $54.5 \%$ (6.7) respectively.

\section{Prepubescent children}

There was no difference in activity levels between boys and girls with the same severity of CF disease (see tables 2 and 3). Similarly, there were no differences in activity levels between boys and girls in the control group (see tables 2 and 3 ).

As a group, prepubescent children with CF were just as active as controls (activity diary: CF, 11.49 (1.18) MJ/day; controls, 11.31 (1.15) MJ/day; accelerometer counts: CF, 8680 (290) units; controls, 8450 (277) units). However, boys and girls with mild CF disease were significantly more active than their respective controls ( $p<0.01$, both groups). Boys and girls with CF and moderate to severe lung disease had activity levels that were not significantly different to the control group (table 2 ).

\section{Pubescent children}

Habitual activity levels, measured by activity diary and accelerometer counts, were significantly less in girls than boys with the same severity of CF disease (tables 2 and 3). Similarly, in the control group, girls were significantly less active than boys $(p<0.05)$. This gender difference in activity levels was not evident in children pre-puberty.

As a group, pubescent children with CF were equally as active as controls (activity diary: CF, 12.78 (2.65) MJ/day; controls, $12.75(2.78) \mathrm{MJ} /$ day; accelerometer counts: CF, 10100 (283) units; controls 10206 (277) units). However, similar to the younger age group, pubescent boys and girls with mild CF disease were significantly more active than controls $(p<0.01$ both groups $)$. However, unlike in the younger age group, pubescent boys and girls with moderate to severe CF disease were significantly less active than controls $(\mathrm{p}<0.05)$. 
Table 1 Demographic details

\begin{tabular}{|c|c|c|c|c|}
\hline & \multicolumn{2}{|c|}{ Prepubescent group } & \multicolumn{2}{|c|}{ Pubescent group } \\
\hline & $\begin{array}{l}\text { CF } \\
(n=70)^{*}\end{array}$ & $\begin{array}{l}\text { Matched } \\
\text { controls } \\
(\mathrm{n}=70)\end{array}$ & $\begin{array}{l}\text { CF } \\
(n=78) \dagger\end{array}$ & $\begin{array}{l}\text { Matched } \\
\text { controls } \\
(\mathrm{n}=78)\end{array}$ \\
\hline Age (years) & $10.9(0.9)$ & $11.0(0.8)$ & $14.3(1.4)$ & $14.2(1.3)$ \\
\hline Weight $(\mathrm{kg})$ & $35.9(3.9)$ & $36.2(3.3)$ & $55.1(6.5)$ & $57.5(6.7)$ \\
\hline Height $(\mathrm{cm})$ & $142(4.6)$ & $143(4.1)$ & $162(7.9)$ & $163(8.5)$ \\
\hline Breastł (females only) & $0.8(0.2)$ & $0.7(0.3)$ & $3.9(0.4)$ & $4.0(0.3)$ \\
\hline Genital‡ (males only) & $0.7(0.2)$ & $0.8(0.2)$ & $3.8(0.4)$ & $3.8(0.3)$ \\
\hline Pubic hair $¥$ (both genders) & $0.6(0.3)$ & $0.7(0.3)$ & $3.8(0.3)$ & $3.9(0.3)$ \\
\hline
\end{tabular}

\section{Activity levels and other parameters of assessment}

There were significant differences between the mild and moderate to severe groups in terms of BMP, aerobic capacity, anaerobic power, quality of life, and lung function (table 3 ). Overall, activity levels of children with CF correlated best with anaerobic power $\left(r^{2}=0.63, \mathrm{p}<0.01\right)$, aerobic capacity $\left(r^{2}=0.55, \mathrm{p}<0.01\right)$, and quality of wellbeing $\left(r^{2}=0.61\right.$, $\mathrm{p}<0.01)$. BMP correlated less well with activity levels $\left(r^{2}=0.20, \mathrm{p}<0.05\right)$. Lung function $\left(\mathrm{FEV}_{1}\right)$ correlated poorly with activity levels $\left(r^{2}=0.08\right)$. However, in patients with moderate to severe disease the best correlates with activity levels were anaerobic power $\left(r^{2}=0.64\right)$, aerobic capacity $\left(r^{2}=0.51\right)$, quality of wellbeing $\left(r^{2}=0.49\right)$, and BMP $\left(r^{2}=0.45\right)$.

The best predictors of activity levels, in descending order of importance, were anaerobic power, aerobic capacity, quality of wellbeing, and nutrition. Children with the highest activity levels ( $100 \%$ activity quartile) had significantly better anaerobic power, aerobic capacity, quality of life, and nutritional status than children with lower activity levels (table 4). In addition, these variables were significantly less in children with the lowest activity level (25\% activity quartile) compared to children in the $50 \%$ and $75 \%$ activity quartiles.

\section{Pancreatic sufficient versus pancreatic insufficient}

In prepubescent children there were no significant differences between children with PS or PI in terms of the assessed variables (table 5). In pubescent children, girls with PS were significantly better than girls with PI for all fitness, nutrition, and quality of life variables $(p<0.05)$, while the only statistically significant differences between PS and PI boys in this age group were better nutrition and quality of life scores $(\mathrm{p}<0.05)$ (table 5$)$.

\section{DISCUSSION}

In this study, we have shown that the habitual activities of prepubescent boys and girls with CF were similar to each other. However, after the onset of puberty, girls with CF were significantly less active than their male counterparts. This pattern of gender difference was similar in the healthy controls.

We have previously shown that the annual decline in lung function was greater in adolescent girls with CF than boys. ${ }^{30}$ While girls with CF are following similar patterns as their healthy peers in being less active than boys, the consequences of reduced habitual activity may be greater. Without an interventional trial, it is not possible to tease out the cause and effect of low habitual activity. However, there appears to be a close association between gender differences in habitual activity and decline in lung function.

The best correlates with activity levels were anaerobic power, aerobic capacity, quality of wellbeing, and nutrition. The excellent correlation between anaerobic power and habitual activity is not surprising given that typically, children's activity is performed in short bursts, and therefore a predominantly anaerobic pathway is employed by the muscles to obtain energy. This is the first study to show the clinically plausible relation between quality of life and habitual activity in children with CF.

Nutritional status correlated well with activity levels in children with moderate to severe disease. This is consistent with previously shown effects of malnutrition in severe disease, resulting in reduced muscle mass and impaired

\begin{tabular}{|c|c|c|c|c|}
\hline & \multicolumn{4}{|c|}{ Activity levels (MJ/day) } \\
\hline & \multicolumn{2}{|l|}{ Prepubescent } & \multicolumn{2}{|l|}{ Pubescent } \\
\hline & Girls & Boys & Girls & Boys \\
\hline $\begin{array}{l}\text { Control } \\
\text { Total CF }\end{array}$ & $\begin{array}{l}10.8(1.8)(n=38) \\
11.0(1.8)(n=38)\end{array}$ & $\begin{array}{l}11.8(1.6)(n=32) \\
12.2(1.9)(n=32)\end{array}$ & $\begin{array}{l}11.3(1.4)(n=37) \\
11.7(1.3)(n=37)\end{array}$ & $\begin{array}{l}13.8(1.7)(n=41) \\
13.9(1.6)(n=41)\end{array}$ \\
\hline $\begin{array}{l}\text { Mild CF } \\
\text { Moderate to } \\
\text { severe CF }\end{array}$ & $\begin{array}{l}12.6(1.7)^{*}(n=22) \\
10.9(1.6)(n=16)\end{array}$ & $\begin{array}{l}13.2(1.2)^{*}(n=17) \\
12.0(1.2)(n=15)\end{array}$ & $\begin{array}{r}13.2(1.2)^{*}(n=21) \\
9.7(1.2)^{*}(n=16)\end{array}$ & $\begin{array}{l}14.9(1.2)^{*}(n=26) \\
12.0(1.5)^{*}(n=15)\end{array}$ \\
\hline \multicolumn{5}{|c|}{$\begin{array}{l}\text { All values shown are mean (SE). } \\
\text { *Indicates significantly different from control value }(\mathrm{p}<0.05) \text {. } \\
\mathrm{n} \text { indicates the number of subjects studied in each group. } \\
\text { Mild disease severity }=\mathrm{FEV}{ }_{1} \geqslant 70 \% \text { predicted. } \\
\text { Moderate to severe disease severity }=\mathrm{FEV}_{1}<70 \% \text { predicted. }\end{array}$} \\
\hline
\end{tabular}


Table 3 Nutrition, measures of fitness, and quality of life in children with cystic fibrosis according to age and disease severity

\begin{tabular}{|c|c|c|c|c|}
\hline & \multicolumn{2}{|c|}{ Mild disease severity } & \multicolumn{2}{|c|}{ Moderate to severe disease severity } \\
\hline & Prepubescent & Pubescent & Prepubescent & Pubescent \\
\hline \multicolumn{5}{|l|}{ Girls } \\
\hline BMP (\%) & $97.6(15.9)$ & $96.9(13.2)$ & $74.0 *(14.9)$ & $68.9^{*}(12.5)$ \\
\hline Aerobic capacity (ml/kg/min) & $42.0(7.6)$ & $45.3(8.6)$ & $40.7^{*}(6.9)$ & $36.2^{*}(5.9)$ \\
\hline Anaerobic power (watts/kg LBM) & $9.8(1.8)$ & $10.2(1.9)$ & $9.2(1.5)^{*}$ & $9.4(1.6)^{*}$ \\
\hline Activity counts (units) & $9200(290)$ & $11200(250)$ & $8100(280)^{*}$ & $9400(260)^{*}$ \\
\hline Quality of wellbeing score & $0.92(0.08)$ & $0.93(0.07)$ & $0.73^{*}(0.16)$ & $0.70 *(0.13)$ \\
\hline \multicolumn{5}{|l|}{ Boys } \\
\hline BMP (\%) & $98.6(13.2)$ & $99.9(11.6)$ & $75.4^{*}(13.6)$ & $65.7^{*}(11.6)$ \\
\hline Aerobic capacity (ml/kg/min) & $44.0(8.5)$ & $52.3(7.9)$ & $39.4^{*}(6.4)$ & $38.3^{*}(6.8)$ \\
\hline Anaerobic power (watts/kg LBM) & $9.9(1.7)$ & $12.4(1.8)$ & $9.4(1.7)^{*}$ & $10.9(1.6)^{*}$ \\
\hline Activity counts (units) & $9400(260)$ & $11800(270)$ & $8400(280)^{*}$ & $9900(260)^{*}$ \\
\hline Quality of wellbeing score & $0.93(0.07)$ & $0.94(0.06)$ & $0.70 *(0.13)$ & $0.68^{*}(0.14)$ \\
\hline \multicolumn{5}{|c|}{$\begin{array}{l}\text { All values shown are mean (SE). } \\
\text { *Significant difference between mild and moderate to severe disease severity in children of the same gender and } \\
\text { age group }(\mathrm{p}<0.05) \text {. } \\
\text { Mild disease severity }=\mathrm{FEV} \mathrm{V}_{1} \geqslant 70 \% \text { predicted. } \\
\text { Moderate to severe disease severity }=\mathrm{FEV},<70 \% \text { predicted. }\end{array}$} \\
\hline
\end{tabular}

functional ability. ${ }^{31-33}$ Our study has shown for the first time that there were significantly lower levels of activity, anaerobic power, aerobic capacity, and quality of life in girls with established puberty with PI compared with those who were PS. These differences were not demonstrable in boys in either of the two age groups. While it may be argued that the sample size may have been too small to detect a difference in the boys, the sample size was similar in girls where the difference was detected. It has previously been shown that boys with PI are better able to maintain nutrition than girls who have PI. ${ }^{34}{ }^{35}$ It may be that with the onset of puberty, the increased nutritional demands for muscle and bone growth result in relative deficiencies of micronutrients required for activity. These deficiencies may be exacerbated in girls by poorer oral intake and/or hormonal changes.

Compared to other habitual activity studies in $\mathrm{CF}^{13}{ }^{14}$ this study is unique in that a large sample of children with CF and matched healthy controls were studied. Unlike in previous studies, children with moderate to severe disease were included. In addition, by using accelerometers, our study was not totally reliant on self report measures but also objective measures of habitual activity. Our study is the first to assess the relations between habitual activity and anaerobic power and quality of life.

In our study the modified Bouchard activity diary, the only activity diary that has been validated using doubly labelled water, ${ }^{27}$ was used to estimate activity levels. Habitual activity data were collected for two non-consecutive weeks. The assigned energy costs for the activity diary were based on published data. ${ }^{28}{ }^{29}$ If the energy cost of a given activity for a patient with CF is greater than that of healthy controls, ${ }^{36}$ this may have been a confounding variable. However, the increased energy cost of activity has only been shown in patients with severe CF disease and not in those with mild disease. ${ }^{37}{ }^{38}$ Previous studies on habitual activity in children with $\mathrm{CF}^{89}$ utilised activity questionnaires to report the intensity of the activity undertaken. However, the energy cost of a given activity in patients with CF is estimated from healthy subjects. This assumption of equity in energy cost may be erroneous. In our study, data on habitual activity were obtained using both a rigorous activity diary and an accelerometer. ${ }^{13}{ }^{14}$ As the prediction equations that convert raw activity counts to energy expenditure have not been validated in $\mathrm{CF}$, only the raw activity counts were presented in this study. The data from the accelerometer is invaluable in that it provides proof of activity reported in the activity diary.

Using accepted definitions, ${ }^{16}$ we studied the prepubescent and pubescent groups separately. This was done because it is clear from the work by Livingstone and colleagues ${ }^{29}$ that total energy expenditure after the onset of puberty is very different to that pre-puberty. In addition, there is a clinical need to identify risk factors that may lead to the increased morbidity and mortality still seen in girls late in their teen years. ${ }^{56}$

By monitoring heart rate, a previous study estimated total daily energy expenditure (not just habitual physical activity) and postulated that children with CF compensated for their increased resting energy expenditure by being less physically active during the day. ${ }^{39}$ Our study and other studies ${ }^{89}$ have failed to support this hypothesis. The differences in results may be due to previously shown inaccuracies in converting heart rate to energy expenditure. ${ }^{27}$ Eliakim and colleagues ${ }^{40}$ measured the effect of training on total energy expenditure in non-obese prepubescent American girls using doubly labelled water. As we only measured habitual activity and not total

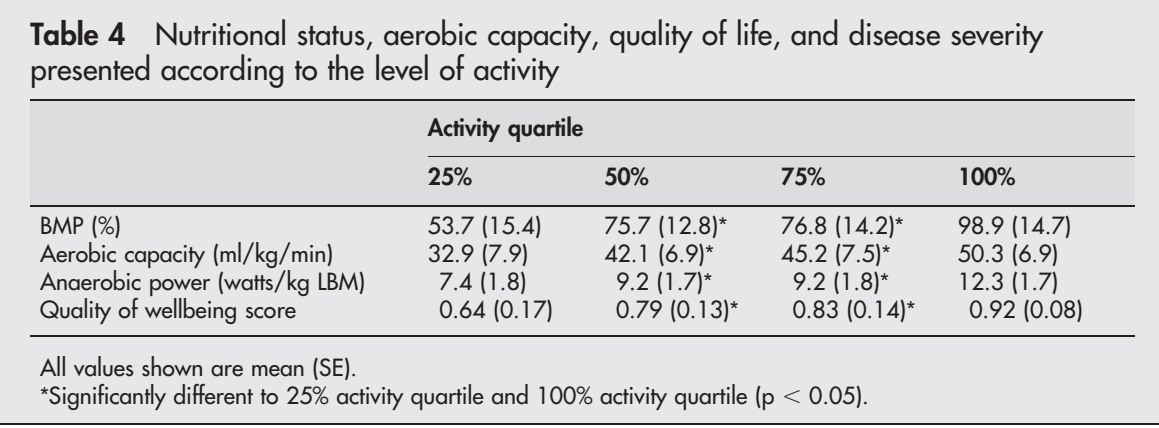


Table 5 A comparison of children with pancreatic insufficiency (PI) and pancreatic sufficiency (PS)

\begin{tabular}{|c|c|c|c|c|c|c|c|c|}
\hline & \multicolumn{2}{|c|}{ Boys (prepubescent) } & \multicolumn{2}{|c|}{ Girls (prepubescent) } & \multicolumn{2}{|c|}{ Boys (pubescent) } & \multicolumn{2}{|c|}{ Girls (pubescent) } \\
\hline & PI $(n=14)$ & PS $(n=7)$ & PI $(n=12)$ & PS $(n=6)$ & PI (n= 12) & PS $(n=6)$ & $\operatorname{PI}(n=16)$ & PS $(n=8)$ \\
\hline BMP (\%) & $98.0(4.1)$ & $98.5(4.3)$ & 97.3 (3.9) & $98.0(3.7)$ & $96.8 *(2.6)$ & $99.5^{*}(2.6)$ & $92.0 *(2.7)$ & $101.3^{*}(3.6)$ \\
\hline Activity level (MJ/day) & $12.2(1.9)$ & $12.5(2.1)$ & $11.0(1.8)$ & $11.2(2.1)$ & $13.9(2.9)$ & $14.1(2.7)$ & $12.0 *(2.6)$ & $13.1^{*}(2.6)$ \\
\hline Activity count (units) & $9500(265)$ & $9650(243)$ & $9100(231)$ & $9300(225)$ & $11100(275)$ & $11310(264)$ & $9600 *(248)$ & $10890^{*}(267)$ \\
\hline Aerobic capacity $(\mathrm{ml} / \mathrm{kg} / \mathrm{min}$ ) & $42.6(7.5)$ & $44.2(9.2)$ & $39.7(8.1)$ & $41.2(8.1)$ & $44.8(8.3) \dagger$ & $45.5(2.9) \ddagger$ & $29.9(2.2)^{*} \dagger$ & $34.6(2.1)^{*} \ddagger$ \\
\hline $\begin{array}{l}\text { Anaerobic power (watts/kg } \\
\text { LBM) }\end{array}$ & $9.8(1.6)$ & $10.1(1.8)$ & $9.7(1.8)$ & $9.9(1.8)$ & $11.6(1.7) \dagger$ & $11.7(1.7) \ddagger$ & $10.6(1.7)^{*} \dagger$ & $11.2(1.7)^{*} \ddagger$ \\
\hline Quality of wellbeing score & $0.90(0.12)$ & $0.92(0.11)$ & $0.88(0.11)$ & $0.90(0.12)$ & $0.70(0.09)^{*}$ & $0.82(0.10)^{*}$ & $0.69(0.15)^{*}$ & $0.87(0.11)^{*}$ \\
\hline
\end{tabular}

All values shown are mean (SE).

*Significant difference between pancreatic insufficient and pancreatic sufficient children of same gender $(p<0.05)$.

†Significant difference between genders in children with pancreatic insufficiency.

$\ddagger$ Significant difference between genders in children with pancreatic sufficiency.

energy expenditure, we are unable to make meaningful comparisons. Higher levels of aerobic fitness were noted in our subjects with mild disease than studies that were performed in North America. ${ }^{9}$ While one may postulate that the mild climate in Australia is more conducive than North America to year round exercise/activity, there is no comparative data to confirm this.

Children with CF, who had high activity levels (top quartile for the respective gender and age group), had significantly better anaerobic power, aerobic capacity, quality of life, and nutrition, and significantly lower disease severity than children with low activity levels (lowest quartile). However, consistent with the study by Boucher and colleagues, ${ }^{13}$ our study found that lung function was not related to activity levels. This would suggest that high activity levels do not necessarily reflect the level of lung function and may independently improve outcome. Although our study shows a relation between activity levels and several variables, causality is not inferred.

In conclusion, gender differences in habitual activity were evident after the onset of puberty and were similar in patients with CF and controls. The impact of pancreatic insufficiency was greatest in females after the onset of puberty. The reason for this gender difference is unclear and is the focus of a longitudinal study currently in progress.

\section{Authors' affiliations}

H C Selvadurai, P J Cooper, Department of Respiratory Medicine, The University of Sydney, The Children's Hospital at Westmead (Royal Alexandra Hospital for Children), Westmead, Sydney 2145, New South Wales, Australia

C J Blimkie, Children's Hospital Institute of Sports Medicine, The University of Sydney, The Children's Hospital at Westmead (Royal Alexandra Hospital for Children), Westmead, Sydney 2145, New South Wales, Australia

C M Mellis, P P Van Asperen, Department of Paediatrics and Child Health, The University of Sydney, The Children's Hospital at Westmead (Royal Alexandra Hospital for Children), Westmead, Sydney 2145, New South Wales, Australia

This study was funded in part by the Australian Cystic Fibrosis Foundation and the Children's Hospital Research Institute, Sydney Australia

\section{REFERENCES}

1 Casperson CJ. Physical activity epidemiology: concepts, methods and applications to exercise science. Exerc Sport Sci Rev 1989;17:423-73.

2 Marcotte JE, Grisdale M, Levison H, et al. Multiple factors limit exercise capacity in cystic fibrosis. Pediatr Pulmonol 1986;2:274-81.

3 Coates AL, Boyce P, Muller D, et al. The role of nutritional status, airway obstruction, hypoxia, and abnormalities in serum lipid composition in limiting exercise tolerance in children with cystic fibrosis. Acta Paediatr Scand 1980;69:353-8.

4 Marcotte JE, Canny G, Grisdale R. Effects of nutritional status on exercise performance in advanced cystic fibrosis. Chest 1986;90:375-9.
5 Fitzsimmons $\mathbf{S}$. The changing epidemiology of cystic fibrosis. J Pediatr 1993;122:1-9.

6 Canadian Patient Data Registry 1996-2000, Personal communication, October 2002.

7 Rosenfeld M, Davis R, FitzSimmons S, et al. Gender gap in cystic fibrosis mortality. Am J Epidemiol 1997; 145:794-803.

8 Nixon $\mathrm{P}$, Orenstein D, Kelsey $\mathrm{S}$, et al. The prognostic value of exercise testing in patients with cystic fibrosis. N Engl J Med 1992;327:1785-8.

9 Orenstein DM, Nixon PA. Exercise performance and breathing patterns in cystic fibrosis: male-female differences and influence of resting pulmonary function. Pediatr Pulmonol 1991;10:101-5.

10 Nixon P, Orenstein D, Kelsey S, et al. The prognostic value of exercise testing in patients with cystic fibrosis. N Engl J Med 1992;327:1785-8.

11 Kroger $\mathrm{H}$, Kotaniemi A, Vainio $\mathrm{P}$, et al. Bone densitometry of the spine and femur in children by dual energy $\mathrm{x}$ ray absoptiometry. Bone Miner 1992; 17:75-85.

12 Orenstein DM, Nixon PA, Ross E, et al. The quality of well being in cystic fibrosis. Chest 1989;95:344-7.

13 Boucher GP, Lands LC, Hay JA, et al. Activity levels and the relationship to lung function and nutritional status in children with cystic fibrosis. Am J Phys Med Rehab 1977;76:311-15.

14 Nixon P, Orenstsein D, Kelsey S. Habitual physical activity in children and adolescents with cystic fibrosis. Med Sci Sports Exerc 2001;33:30-5.

15 Numerical Algorithms Group Ltd. Nag manual. Oxford: Oxford Press, 1978.

16 Tanner JM, Whitehouse RH. Clinical longitudinal standards for height, weight, height velocity, weight velocity and stages of puberty. Arch Dis Child 1976:51:170-9.

17 Booth M, Macaskill P, Phongsavan P, et al. Methods of the NSW Schools Fitness and Physical Activity Survey. J Sci Med Sport 1998;1:111-24.

18 Bouchard C, Tremblay A, Leblanc C, et al. A method to assess energy expenditure in children and adults. Am J Clin Nutr 1983:37:461-7.

19 Janz KF. Validation of the CSA accelerometer for assessing children's physical activity. Med Sci Sports Exerc 1995;26:369-75.

20 Melanson EL, Freedson PS. Validity of the Computer Science and Applications Inc. (CSA) activity monitor. Med Sci Sports Exerc 1995;27:934-40.

21 Freedson PS, Melanson E, Sirard J. Calibration of the Computer Science and Applications Inc. accelerometer. Med Sci Sports Exerc 1998;30:777-81.

22 Durnin JVGA, Rahaman MM. The assessment of the amount of fat in the human body from measurements of skinfold thickness. Br J Nutr 1967;21:681-9.

23 Orenstein DM, Nixon PA, Ross EA. The quality of well being in cystic fibrosis. Chest 1989;92:344-7

24 Bruce RA. Exercise testing of patients with coronary heart disease: principles and normal standards. Ann Clin Res 1971;3:323-32.

25 Ayalon A, Inbar O, Bar-Or O. Relationships among measurements of explosive strength and anaerobic power. In: Nelson RC, Morehouse CA, eds. International series on sport sciences (Vol 1. Biomechanics IV). Baltimore: University Park Press, 1974:572-7.

26 Polgar G, Promadhat V. Standards in pulmonary function tests. In: Polgar G, ed. Pulmonary function testing in children; techniques and standard. Philadelphia: WB Saunders, 1971:254-60.

27 Bratteby LE, Sandhagen B, Fan $\mathrm{H}$, et al. A 7 day activity diary for assessment of daily energy expenditure validated by the doubly labelled water method in adolescents. Eur J Clin Nutr 1997;51:585-91.

28 Ainsworth BE, Haskell WL, Leon AS, et al. Compendium of physical activities: classification of energy costs of human physical activities. Med Sci Sports Exerc 1993;25:71-80.

29 Livingstone MBE, Coward WA, Prentice AM, et al. Daily energy expenditure in free living children: comparison of heart rate monitoring with doubly labelled water method. Am J Clin Nutr 1992;56:343-52

30 Wilkes D, Schneiderman Walker J, Selvadurai HC, et al. Habitual activity and decline in lung function [abstract 313]. Pediatr Pulmonol 2002;(suppl 2).

31 Lands LC, Heigenshauser GJ, Jones N. Analysis of factors limiting exercise performance in cystic fibrosis. Clin Sci 1992;83:391-7.

32 Marcotte JE, Grisdale R, Levison $\mathrm{H}$, et al. Multiple factors limit exercise capacity in cystic fibrosis. Pediatr Pulmonol 1986;2:274-81.

33 Russell DM, Walker PM, Leiter LA, et al. Metabolic and structural changes in skeletal muscle during hypocaloric dieting. Am J Clin Nutr 1984;39:503-13. 
34 Kraemer R, Rudeberg A, Hadom B, et al. Relative underweight in cystic fibrosis and its prognostic value. Acta Paediatr Scand 1978;67:33-7.

35 Gaskin K, Gurwitz D, Durie P, et al. Improved respiratory prognosis in patients with normal fat absorption. J Pediatr 1982;100:857-62.

36 Grunow J, Azcue M, Berall G, et al. Energy expenditure in cystic fibrosis during activities of daily living. J Pediatr 1993;122:243-6.

37 Richards M, Davies P, Bell S. Energy cost of physical activity in cystic fibrosis. Eur J Clin Nutr 2001;55:690-7.
38 Tomezsko JL, Stallings VA, Kawchak DA, et al. Energy expenditure and genotype of children with cystic fibrosis. Pediatr Res 1994;35:451-60

39 Spicher V, Roulet $M$, Schutz Y. Assessment of total energy expenditure in free living patients with cystic fibrosis. J Pediatr 1991;118:865-72.

40 Eliakim A, Scheet T, Allmendinger N, et al. Training, muscle volume and energy expenditure in non-obese American girls. J Appl Physiol $2001 ; 90: 35-44$.

\section{ARCHIVIST}

\section{John Newport Langley and drug receptor theory}

W

ith the isolation of receptor proteins from cell membranes in the 1970s and the subsequent definition of receptor genes receptor theory became fact but a hundred years ago there was much controversy about the site and nature of drug action. In 1905 John Newport Langley, professor of physiology in Cambridge, described his concept of "receptive substances" as mediators of drug action in a paper in the Journal of Physiology that can be seen as the foundation of drug receptor theory (Andreas-Holger Maehle. Medical History 2004;48:153-74).

In animal experiments in the 1870s Langley had shown that jaborandi, a plant extract containing pilocarpine, slowed the heart, the effect was reversed by atropine, and both effects were independent of vagus nerve function. Similarly pilocarpine stimulated the secretion of saliva and atropine inhibited it. In both heart and salivary gland experiments the effect depended on the amount of each drug present. Langley concluded that pilocarpine and atropine formed "chemical compounds" with tissue components, the end result depending on "their relative chemical affinity to the tissue and the mass of each present". The drugs each reacted with the tissue cells one having a positive and one a negative effect [agonists and antagonists or inhibitors in modern terminology].

At the turn of the century there was considerable controversy about whether drugs such as nicotine, curare, pilocarpine, and atropine acted directly on muscle or gland cells or through nerve endings. In experiments on denervated striated muscle Langley showed that nicotine still produced tonic contraction that was relaxed by curare, and direct electrical stimulation of the muscle produced muscle contraction after injection of either drug. Langley wrote, "neither the poisons nor the nervous impulse act directly on the contractile substance of the muscle but on some accessory substance" and "since this accessory substance is the recipient of stimuli which it transfers to the contractile material, we may speak of it as the receptive substance of the muscle". He was thus postulating the existence of receptors. Moreover, he generalised the idea, suggesting that all cells had a "chief substance" concerned with the cell's main function, such as contraction or secretion, and receptive substances that were acted upon by chemical or nervous stimuli and regulated the metabolism of the chief substance. The theory of drug receptors had arrived. Ehrlich who had described "side chain" receptors in immunology was at first resistant to the idea of drug receptors but in 1907 he too proposed the existence of drug "chemoreceptors". Langley's theories were much debated at the time and receptors remained theoretical until the discoveries of the 1970s.

Langley was born in 1852 and died in 1925. He was a journal editor (Journal of Physiology, 1894-1925), scientific luminary (FRS 1883, president of the Neurological Society of Great Britain 1893, president of the physiological section, British Association for the Advancement of Science 1899, vice president, Royal Society 1904), and talented ice skater (he devised official rules for the sport and acted as an appeal judge in international competitions). He went to Cambridge as an undergraduate in 1871 and spent the whole of his career there. 